\title{
EDITORIALS
}

\section{Institutional ethics committees: critical gaps}

\author{
GEORGE THOMAS
}

Head of Emergency Services, St Isabel's Hospital, Oliver Rd, Chennai 600004 INDIA e-mail: george.s.thomas@gmail.com

The guidelines issued in 2006 by the Indian Council for Medical Research in India (1), for the formation and conduct of clinical trials in India, are still the benchmark by which the conduct of such trials is evaluated. Unfortunately, these guidelines have not yet got the force of law, since the bill is still pending in Parliament. An important section of the guidelines pertains to the constitution and conduct of the committees which should examine, permit and monitor clinical research in India. Information on how well the committees are functioning is not easily available. Personal observation and conversations with members of ethics committees in other institutions have revealed certain serious lacunae, which have the potential to entirely subvert the purpose of these committees. These concerns are:

\section{Scientific review}

The ICMR guidelines state:

The basic responsibility of an Institutional Ethics Committee (IEC) is to ensure a competent review of all ethical aspects of the project proposals received by it in an objective manner. IECs should provide advice to the researchers on all aspects of the welfare and safety of the research participants after ensuring the scientific soundness of the proposed research through appropriate Scientific Review Committee [emphasis added]. In institutions where this is lacking, the IEC may take up the dual responsibility... (1:8)

The design of clinical research projects has become a complex affair, with much care taken to ensure that chance, bias and other errors do not vitiate the collection of data, and its interpretation. This is an ongoing process and there is much debate still going on as to how best to acquire data that will be true. It is a moot point whether most medical institutions in India have expertise in the design of clinical trials. Even institutions like the All India Institute of Medical Sciences, the Post Graduate Institute of Medical Education and Research, and the Jawaharlal Institute of Postgraduate Medical Education and Research -- all of which have been set up with a research component as part of their mandate -- seem to have inconsistent policies which result in some departments having a high degree of competence in the area and others showing a remarkable ignorance. In the educational institutions managed by various state governments, very few have institutional arrangements for training in research and many researchers learn methodology on their own. These individual efforts, while laudable, need to be replaced by systematic capacity building if we wish to build a strong research fraternity with exemplary ethical values.

\section{Special situations}

"Small institutions could form alliance with other IECs or approach registered IEC (ind)." (1:8)

Apparently this provision has been included to help researchers working independently or in small institutions which do not have the resources to set up their own committees. It is not clear, however, why anyone would set up an independent ethics committee, except for profit.

It is also not clear who would register such independent review boards. A few such committees have already been set up in India. Informal reports say that they never turn down any proposal. If this is indeed true, then trials which are risky for patients may be conducted. The experience of the United States with the Coast IRB of Colorado Springs should be kept in mind (2). Strict oversight and audit of trials being cleared should become part of the remit of any overarching organisation being set up for research. At present the ICMR does not have the resources required for such oversight.

\section{Composition}

"The IECs should be multidisciplinary and multisectoral in composition. Independence and competence are the two hallmarks of an IEC." (1:9) 
The laudable objective of ensuring that various facets of society are represented by insisting on having non-medical people in the IECs, and mandating that a lawyer or judge, social scientist or representative of a non-governmental voluntary agency, a philosopher/ethicist/theologian and a lay person from the community should all be on the IEC, seems not to be achieving the purpose of a broad consultation. It appears that, often, the non-medical persons on the committee are in awe of the medical persons and speak little. The idea of 'discourse ethics' as elucidated by Jurgen Habermas and Karl Otto-Apel seems to be absent. It appears that capacity building is needed here too. Developing and encouraging expertise in the field of ethics is an urgent necessity.

\title{
Monitoring
}

"Once IEC gives a certificate of approval it is the duty of the IEC to monitor the approved studies, therefore an oversight mechanism should be in place." (1:19)

It is doubtful if many (or even any) IECs in the country are following this guideline. At least some members of the IEC would have to work full time on only the IEC in order to be able to effectively monitor trials, especially in large organisations like the AlIMS where a large number of trials are carried out.

\section{Conclusion}

The ICMR Ethical Guidelines for Biomedical Research on Human Participants is a strong starting point for the oversight and safe conduct of clinical trials in India. In order to translate intentions into practice, further development of the guidelines is required.

\section{References}

1. Indian Council of Medical Research. Ethical guidelines for biomedical research on human participants [Internet]. New Delhi:ICMR; 2006 [cited 2011 Aug 29]. 111 p. Available from:www.icmr.nic.in/ethical_guidelines.pdf

2. How ethical are for-profit institutional review boards? Lancet. 2009 Apr 25; 373(9673):1400.

\section{Evidence-based medicine: can the evidence be trusted?}

\author{
PRATHAP THARYAN
}

Professor of Psychiatry, Prof BV Moses \& ICMR Centre for Advanced Research in Evidence-Informed Healthcare, Christian Medical College, Vellore 632002, Tamil

Nadu INDIA e-mail: prathap@cmcvellore.ac.in

\begin{abstract}
Empirical research indicates that much of the evidence required for the practice of evidence-based medicine cannot be trusted. The research agenda has been hijacked by those with vested interests within industry and academia, determining what research is funded and how it is done and reported. Unnecessary, inappropriate, or poorly designed and reported research results in suboptimal health outcomes. Many well-reported randomized controlled trials are designed to deceive by their choice of comparators and outcomes, and manipulation of statistics to produce desired outcomes that are selectively reported. Undisclosed conflict of interest, ghostwriting, the manufacturing of disease to increase drug marketing, and the marketing of research disguised as education are common. Understanding the many ways in which research is used to deceive, rather than reliably inform health decisions, and reclaiming the research agenda, is the collective responsibility of the scientific community and civil society.

Evidence-Based Medicine (EBM) refers to the process of making medical decisions that are consistent with evidence from relevant research and envisages a therapeutic alliance between research-evidence, clinicians and patients (1). The linchpin of this alliance is the astute clinician who has the resources and skills to readily access and to critically appraise evidence from research. For the potential benefits of EBM to be fully realized in improved health outcomes for patients, many caveats apply; the most important one is whether the evidence from research can be trusted.
\end{abstract}

